\title{
Analysis on the effects of pre-heating temperature on mechanical properties of pellets made from corn stalk powder
}

\author{
Zhiping Xue, Qingyu Liu*, Peter Emmanuel, Junwei Qin, Dejun Liu, Wei Gao, Yuanjuan Gong, \\ Xuewei Bai
}

Department of Engineering, Shenyang Agricultural University, 110866 Shenyang, China

Email: qyliu@126.com

\begin{abstract}
A mould pressing unit is used to investigate the effects of preheating temperature on the compact characteristics of ground corn stalk. Diameter of $10 \mathrm{~mm}$ mould was used to pellet the corn stalk; the preheating temperature was applied to the forming mould ranges 60 to $180^{\circ} \mathrm{C}$ with $20^{\circ} \mathrm{C}$ interval. Firstly, for each given temperature in experimental processing, it indicates that the sequential maximum force of each compression stroke increased follows the exponential form in close-end compression. The general Maxwell model is found effective in describing the viscous-elastic mechanical property of corn stalk powder. Secondly, the force transition stage from closed-end to open-end compression is resolved. To reach a steady compression stage, the mechanical behaviours should be similar in every stroke. Thirdly, the pelleting stage in open-end compression is studied at different temperatures. This research provides some foundational work for bio-mass solidification, especially for corn stalk pellet production.
\end{abstract}

Keywords: Preheating Temperature, Mechanical Properties, Biomass Pellet, Corn Stalk.

\section{INTRODUCTION}

Corn stalks are usually disposed as agricultural wastes especially in some maize production region. Large quantities of corn stalks were being burned up to avoid delaying sequential tillage. This burning of corn stalks caused serious environmental pollutions and also resulted into traffic accidents because of the heavy smokes produced [1].

On the other hand, bio energy has the ability to reduce greenhouse gas (GHG) emissions by as much as $86 \%$ in comparison with gasoline [2-3]. The use of agricultural residues as energy is a hopeful alternative to mineral fuel resources for the production of energy carriers and chemicals which would thereby reduce climatic change and also enhance energy security [4-5]. But the contribution of these technologies is still low [6].

In China, bio-energy is the third most important source of renewable energy followed by hydroelectric energy and wind energy. The amount of crop straw manufactured in China was 820 million $\mathrm{t}$ (air dried with $\sim 15 \%$ wt. moisture) in the year 2009 , which consists of corn stalks, rice straws, and wheat straws and where the main types residues [7].

However, the high bulk density of biomass usually resulted in high costs of transportation and also in storage. Solidification of biomass into a durable compact form is an effective solution to this problem which helps to reduce material wastes; it also can increase the density from an initial bulk density of $40-250 \mathrm{~kg} / \mathrm{m}^{3}$ to as high as $1200 \mathrm{~kg} / \mathrm{m}^{3}$ [3-4,89]. High quality pellet can be produced by the management of the inventing operations of biomass mechanical and chemical characteristics.

Biomass powder varies in their reaction to the compression forces applied during pelleting. To a much large degree, the qualities of manufactured compacts rely on the physical forces that bind the particles together. Many research works indicate that the strength, stability, and durability of high density biomass increased with increasing water contents until an ideal point is achieved.

Low moisture chopped corn Stover (5-10\% Wet Basis.) resulted in a denser, stable, and highly durable pellet than high moisture Stover (15\% W.B.) [10-11]. As a result of the increase of the compact volume, particles and bulk densities of biomass pellets decreased in line with the increase of moisture content [12-13].

Water plays an important role as a bonding agent by enhancing the bond behavior between stalk particles [14-15]. Water increases the forces of attraction between stalk particles by building a Van der Waals forces between particles and as well as increasing the area of contact between particles [16].

The objective of this study is to experimentally ascertain the effect of preheating temperature on the mechanical properties (density and mechanical behaviors and constitutive model) of pellets produced from ground corn stalk powder. The main aim of this particular raw material is due to the high presence of this material in China. 


\section{EXPERIMENTAL}

\subsection{Materials}

Corn stalk was reaped in the winter season in the year 2015 at the experimental field of the Shenyang Agricultural University after it had being subjected to the light and heat of the sun to dry, thereafter, it was crushed and sieved into particles smaller than $3 \mathrm{~mm}$ in diameter with the use of a milling hammer and screening equipment, and it was then packed in storage boxes with sealed cover.

For adjusting, there is given moisture content which is required to carry out the experiment. A certain amount of water was sprayed and mixed with the material two days before the pelleting test was done.

\subsection{Single pellet testing system}

A setup of mould pressing system was designed and fixed to contain and compact the corn stalk powder with a water content of about $20 \%$ (W.B.). The sectioned view of the mould pressing unit is shown in Figure. 1.

The milled corn powder is filled into the hole with a diameter of $10 \mathrm{~mm}$ of mould which is encompassed by a heating coil. At the bottom of the mould, a thermal sensor is inserted into the hole near the forming cavity to detect its temperature and a conductive epoxy is filled between the parts in contact to enable heat transfer.

The compression bar is clamped by a chuck and driven by universal testing system (type of wdw-200, Shandong, China).

There are two types on compression, namely:

- closed end compression, in which the ending bar blocks the mould cavity;

- open end compression, in which the ending bar is removed.

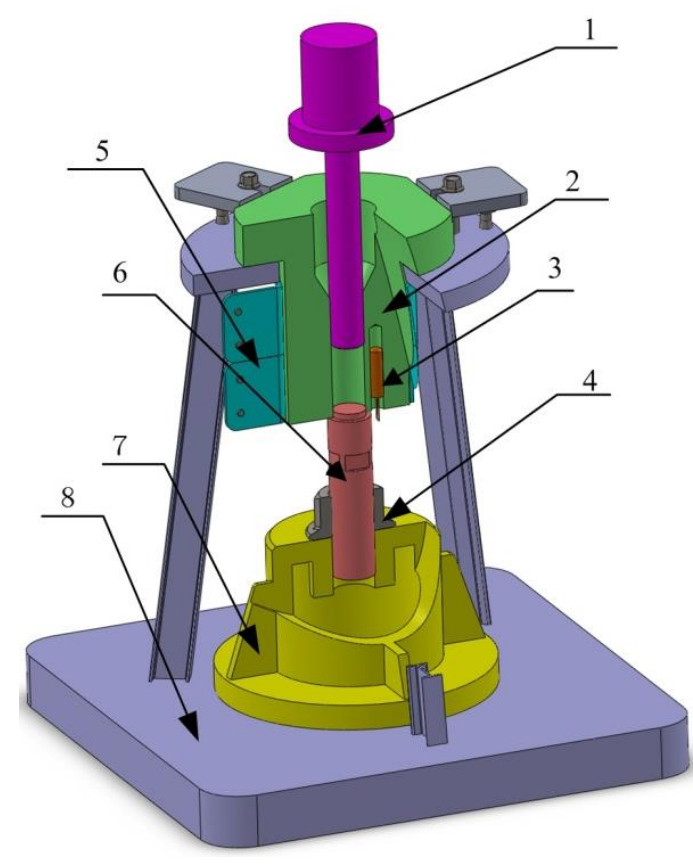

Figure 1. Setup of mould pressing unit

Notes: 1 - compressing bar; 2 - mould; 3 - thermal couple; 4 - adjusting nut; 5 - heater; 6 - ending bar; 7 - supporting seat; 8 - welded frame

\section{RESULTS AND DISCUSSION}

\subsection{Influence and preheating temperature on particles and pellets shape and stability}

Figure 2 shows that pellets made from corn stalk powder in mould cavity are given by seven levels of temperature, ranging from 60 to $180{ }^{\circ} \mathrm{C}$ with an interval of $20^{\circ} \mathrm{C}$. With the preheating temperature increased from 60 to $120^{\circ} \mathrm{C}$, corn stalk particles bounded gradually together and the surficial smoothness of the pellets increased, also, the pellets geometrical shape tends to be straighter and rigid than it does at normal temperature [17].

However, the forces of adhesion between corn stalk particles became lower when the temperature is higher than $120^{\circ} \mathrm{C}$; particles hardly maintained a stationary form when the temperature reached $180{ }^{\circ} \mathrm{C}$. With a moisture content of $20 \%$, it's hard for a pellet to be formed if the preheating temperature exceeds $120{ }^{\circ} \mathrm{C}$, and the corresponding forces of attraction reduced rapidly due to the evaporating of water in the corn stalk material.

On the contrary, the pellets tend to crack and posses a rough surface when the preheating temperature is lower than $60{ }^{\circ} \mathrm{C}$.

Therefore, a temperature range from 80 to $120{ }^{\circ} \mathrm{C}$ is used to produce a pellet with a smooth surface and a density of 1.0 $\mathrm{g} / \mathrm{cm}^{3}$ in the experiment.

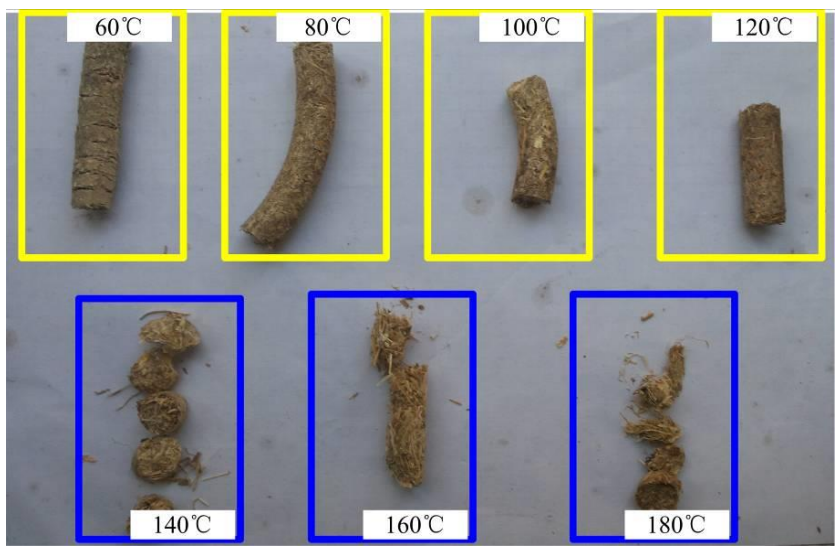

Figure 2. Pellets produced at a given temperature

\subsection{Influence and preheating temperature on particles and pellets shape and stability}

The enhancement of the pellets density is an important target for compacting biomass. In this experiment, temperature is investigated and other parameters such as the moisture contents, mould hole diameter, and so on, set in common use and held constant. The densities of the pellets are measured after $24 \mathrm{~h}$ since it has being extruded.

As shown in Figure 3, mould cavity temperature has an important role to play in producing biomass pellets. The density decreased from about $1.0 \mathrm{~g} / \mathrm{cm}^{3}$ steady to $0.9 \mathrm{~g} / \mathrm{cm}^{3}$ with a temperature ranging from 60 to $120^{\circ} \mathrm{C}$. Then, the density goes down rapidly until the temperature increased to $160{ }^{\circ} \mathrm{C}$, and it will be close to the value of approximately below $0.3 \mathrm{~g} / \mathrm{cm}^{3}$ in the loose and dry state. 


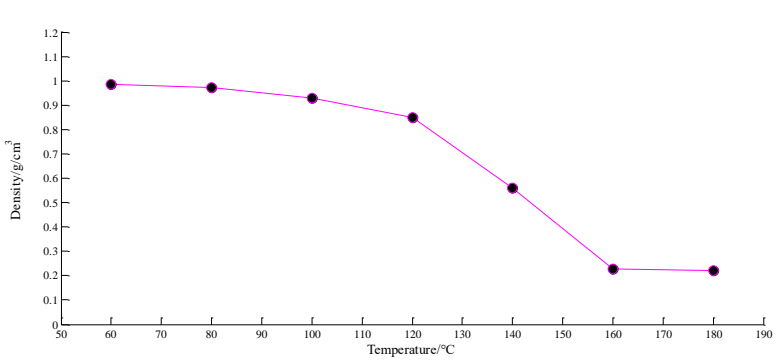

Figure 3. Graph of density change with temperature

\subsection{Force-time relationship in corn stalk powder compaction}

The compressive force is a major factor with an important influence in the course of compacting pellets. Figure 4 shows the compressive force changes over time at a specific temperature.

The pellet forming process consists of two phases namely: close-end compression phase, and open-end compression phase.

The close-end compression phase is the first phase in pellet forming in which there is an ending bar blocking the phase cavity and it is essential to build the forming conditions. There are 12 strokes in close-end compression phase.

The second phase is the open-end compression phase, which implies that the ending bar of the mould pressing setup is removed. It determines whether the pellet making operation process is achieved.

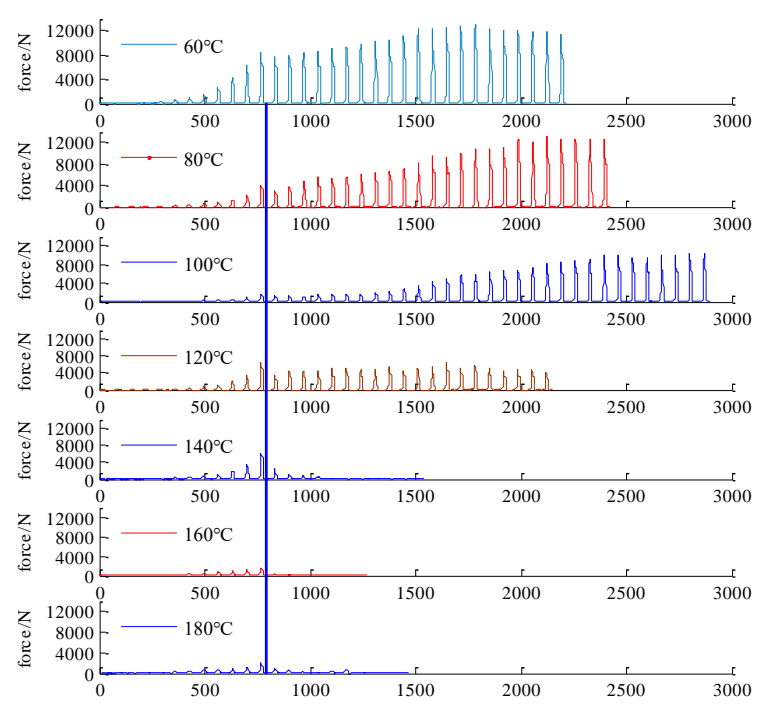

Figure 4. Force against time at a given temperature

12 compressions on the left side of line are close-end mode, and the right side is open-end compression mode

3.3.1 Maximum force of each compression stroke in closeend compression phase

In the close-end compression phase, the compression bar progresses at the speed of $100 \mathrm{~mm} / \mathrm{min}$ and the compressive force $F$ increased with time $t$ following the exponential form:

$F=A \mathrm{e}^{B t}$

where $A$ and $B$ are constant parameters determined by empirical data.
Table 1 listed the coefficients $A$ and $B$ of the model at each temperature, respectively. The maximum force $F_{\max }$ and corresponding time $t_{\max }$ in the last stoke of close-end compression are also listed. The maximum compacting force changed at a wide range from $8472 \mathrm{~N}$ at a preheating temperature of $60{ }^{\circ} \mathrm{C}$ to $1665 \mathrm{~N}$ at $100{ }^{\circ} \mathrm{C}$. The wide range of change of temperature is caused by the coupling effect of heat and moisture content.

When compacting at a lower temperature level, the evaporation of water is slower than it does at higher temperature. The water plays an important role as a combing agent by enhancing the bonding behavior, the contact area between the particles is also increased which results in a higher density and also a higher counter acting force.

On the contrary, once the water evaporates too fast, the cohesive force gives rise to a less bonding force between particles which leads to a loose state with big rebounding deformation.

Table 1. Parameters of maximum force-time model

\begin{tabular}{cccccc}
\hline$T\left({ }^{\circ} \mathrm{C}\right)$ & $A$ & $B$ & $t_{\max } / \mathrm{s}$ & $F_{\max } / \mathrm{N}$ & $R$-square \\
\hline 60 & 90.63 & 0.00598 & 765.4 & 8472 & 0.993 \\
80 & 17.63 & 0.00705 & 766.4 & 3967 & 0.998 \\
100 & 17.59 & 0.00617 & 766.2 & 1665 & 0.986 \\
120 & 8.911 & 0.00856 & 765.0 & 6270 & 0.998 \\
140 & 20.83 & 0.00739 & 766.0 & 6038 & 0.998 \\
160 & 46.03 & 0.00473 & 766.0 & 1709 & 0.995 \\
180 & 57.62 & 0.00453 & 766.2 & 1889 & 0.987 \\
\hline
\end{tabular}

\subsubsection{Compacting analysis on single stroke.}

As far as single stroke is concerned, the force and deformation displays a similar performance whether in closeend or open-end compression phase. A typical deformation and force against time curve is shown in Figure. 5 which is the 34th compression stroke in mould cavity diameter of 10 $\mathrm{mm}$ with moisture content of $20 \%$ (W.T) and preheating temperature set to $80^{\circ} \mathrm{C}$.

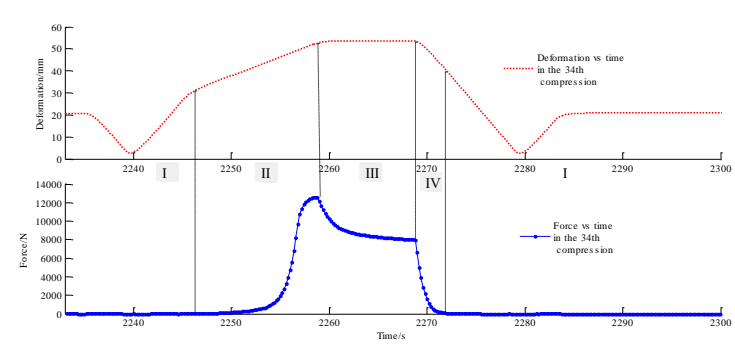

Figure 5. Deformation and force against time in compression (temperature of $80^{\circ} \mathrm{C}$ )

According to the deformation feature and corresponding mechanical behaviors, it is divided into 4 stages.

In stage I, the compression bar pushes towards the bulky corn stalk powder with a velocity of $200 \mathrm{~mm} / \mathrm{min}$ until it comes in contact with the biomass material.

Stage II is characterized by squeezing and pushing material with a velocity of $100 \mathrm{~mm} / \mathrm{min}$, it is the critical stage for particle bonding and consolidation, the advancing distance in this stage is set to $20 \mathrm{~mm}$.

Stage III begins in which the compression bar pauses after every $10 \mathrm{~s}$ to preserve deformation and release the residual stress. It is defined as stress relation for the internal force descends where there is not any shape changing. 
Stage IV proceeds immediately in which the compression bar goes back and pellet bounded following the end face of compression bar until it achieves a balance.

The separation between material and compression bar means the end of stage IV and the start of stage I indicates the next round of compaction.

3.3.3 Viscoelastic properties and their description in openend compression Phase.

For the open-end compression, a steady compression stage means that the mechanical behavior should be similar in every stroke; otherwise, every increasing compressive force after close-end phase will give rise to material block in engineering.

Conversely, for a gradual drop in compression force, it will result in lack of forming conditions in pellet process. In this work, the compacting force becomes weaker and weaker and the corn stalk powder cannot come into a permanent shape once the temperature is above $120{ }^{\circ} \mathrm{C}$; this phenomenon is also reflected in Figure. 5.

To investigate the mechanical nature over time of corn stalk powder in open-end compression phase, a general Maxwell model is introduced to describe the mechanical behaviour related with time history. The model is composed of a basic Maxwell model [M], which is connected in a series of ideal mechanical spring and slider with the parallel combination of a certain amount of $[\mathrm{M}]$ units and/or spring elements. General Maxwell model usually has sufficient accuracy to simulate viscoelastic properties of the corn stalk powder [18-19].

As previously mentioned, the compression stage III in Figure. 5 meets the basic needs for engineering stress to relation condition. The key to find an appropriate general Maxwell model is to estimate the amount [M] properly and efficient mathematical algorithm to fit the experimental stress relation data.

The stress $\sigma$ is defined as follows:

$\sigma=\frac{F}{A}=\frac{4 F}{\pi d^{2}}$

where $\mathrm{F}$ is the force applied $(\mathrm{N})$; A - the cross sectional area $\left(\mathrm{mm}^{2}\right)$, and $\mathrm{d}$ - the diameter of mould cavity $(\mathrm{mm})$.

Through several calculating attempts using particle swarm optimisation, Quasi-Newton, Powell optimisation and genetic algorithm (G.A.) and so on, the genetic algorithm method is recommended to identify the specific construction and coefficient of general Maxwell model.

The genetic algorithm method belongs to the larger class of evolutionary algorithm (E.A.) which generates solutions to optimization problems using techniques inspired by natural evolution such as inheritance, mutation, selection and crossover [20].

The derivative information is not necessary for genetic algorithm, and simultaneous research can be done in a wide sampling of domain [21-24]. The population size, crossover rate and mutation rate in genetic algorithm is $20,0.85$, and 0.01 , respectively. Uniform crossover operation and random selection methods are employed in the work.

The final general Maxwell model is shown in Figure. 6. It is composed of two Maxwell elements and a spring element.

In Table 2, the initial stress $\sigma_{\max }$ is the maximum stress in process of stress relation and constant terms in the general Maxwell model.

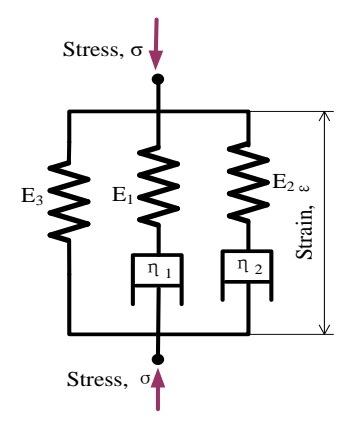

Figure 6. General Maxwell model obtained

Table 2. Parameters of the general Maxwell model

\begin{tabular}{cccccccc}
\hline$T\left({ }^{\circ} \mathrm{C}\right)$ & $\sigma_{\max } / \mathrm{MPa}$ & $\sigma_{1} / \mathrm{MPa}$ & $\tau_{1} / \mathrm{s}$ & $\sigma_{2} / \mathrm{MPa}$ & $\tau_{2} / \mathrm{s}$ & $\sigma_{3} / \mathrm{MPa}$ & $R$-square \\
\hline 60 & 143.20 & 18.04 & 0.10 & 31.13 & 0.74 & 94.03 & 0.999 \\
80 & 103.13 & 14.46 & 0.08 & 16.37 & 0.81 & 72.29 & 0.999 \\
100 & 58.52 & 7.33 & 0.12 & 3.04 & 1.02 & 48.15 & 0.999 \\
120 & 51.23 & 4.97 & 0.17 & 7.22 & 0.91 & 39.04 & 0.999 \\
140 & -- & -- & -- & -- & -- & -- & -- \\
160 & -- & -- & -- & -- & -- & -- & -- \\
180 & -- & -- & -- & -- & -- & -- & -- \\
\hline
\end{tabular}

Table 2 displayed that the preheating temperature played an important role in the pelleting process especially the value $\sigma_{3}$, which take account for more than $65 \%$ of the whole stress being relaxed. It is a representation of solidification degree for the given temperature in the experiment, the highest rate $\sigma_{3}$ to $\sigma_{\max }$ with $82.28 \%$ at $100{ }^{\circ} \mathrm{C}$ is in accordance with experimental result. The pellet is firmer than others with an acceptable density of approximately $1.0 \mathrm{~g} / \mathrm{cm}^{3}$.

\section{CONCLUSIONS}

The compacting characteristics of ground corn stalk powder are affected immensely by preheating temperature applied to the forming mould.

The sequential maximum force of each compression stroke increased following the exponential force in close-end compression.

The general Maxwell model composed of two Maxwell elements and a spring element which was found effective in describing the viscoelastic mechanical property of corn stalk powder. For the given temperature in the experiment, the highest rate $\sigma_{3}$ to $\sigma_{\max }$ with $82.28 \%$ at $100{ }^{\circ} \mathrm{C}$ is desired for its solidification and density of approximately $1.0 \mathrm{~g} / \mathrm{cm}^{3}$.

\section{ACKNOWLEDGEMENTS}

This project was supported by National Natural Science Foundation of China (Grant No 51405311).

\section{REFERENCES}

[1] Mohammed Y. S., Mokhtar A. S., Bashir N., Saidur R. (2013). An overview of agricultural biomass for decentralized rural energy in Ghana, Renewable \& Sustainable Energy Reviews, Vol. 20, No. 4, pp. 1525. DOI: $10.1016 /$ j.rser.2012.11.047 
[2] Song X., Zhang M., Pei Z. J., Wang D. (2014). Ultrasonic vibration-assisted pelleting of wheat straw: a predictive model for energy consumption using response surface methodology, Ultrasonics, Vol. 54, No. 1, pp. 305-311. DOI: 10.1016/j.ultras.2013.06.013

[3] Marcoux H., Smail K., Alain De Champlain, Paquet B. (2013). Influence of a wood stove design on cleaner combustion with reduced particulate and gaseous emissions, International Journal of Heat and Technology, Vol. 31, No. 2, pp.77-80. DOI: 10.18280/ijht.310210

[4] Stolarski M. J., Szczukowski S., Tworkowski J., Krzyżaniak M., Gulczyński P., Mleczek M. (2013). Comparison of quality and production cost of briquettes made from agricultural and forest origin biomass, Renewable Energy, Vol. 57, No. 3, pp. 20-26. DOI: $10.1016 /$ j.renene.2013.01.005

[5] Stelte W., Nielsen N.P.K., Hansen H.O., Shang J. Dahl, L., Sanadi A.R. (2013). Pelletizing Properties of Torrefied Wheat Straw. Biomass Bioenerg, Vol. 49, No. 49, pp. 214-221. DOI: 10.1016/j.biombioe.2012.12.025

[6] Mirandola A., Lorenzini E., (2016). Energy, environment and climate: from the past to the future, International Journal of Heat and Technology, Vol. 34, No. 2, pp. 159-164. DOI: 10.18280/ijht.340201

[7] Hu J., Lei T., Wang Z., Yan X., Shi X., Li Z., He X., Zhang Q. (2014). Economic, environmental and social assessment of briquette fuel from agricultural residues in China - a study on flat die briquetting using corn stalk, Energy, Vol. 64, No. 1, pp. 557-566. DOI: 10.1016/j.energy.2013.10.028

[8] Ramírez-Gómez Á., Gallego E., Fuentes J., GonzálezMontellano C., Ayuga F. (2013). Values for particlescale properties of biomass briquettes made from agroforestry residues, Particuology, Vol. 12, No. 1, pp. 100-106. DOI: 10.1016/i.partic.2013.05.007

[9] Liu Z., Liu X. E., Fei B., Jiang Z., Cai Z., Yu Y. (2013). The properties of pellets from mixing bamboo and rice straw, Renewable Energy, Vol. 55, No. 4, pp.1-5. DOI: 10.1016/j.renene.2012.12.014

[10] Mani S., Tabil L. G., Sokhansanj S. (2006). Effects of compressive force, particle size and moisture content on mechanical properties of biomass pellets from grasses, Biomass and Bioenergy, Vol. 30, No. 7, pp. 648-654. DOI: $10.1016 /$ j.biombioe.2005.01.004

[11] Mani S., Tabil L. G., Sokhansanj S. (2006). Specific energy requirement for compacting corn stover, Bioresource Technology, Vol. 97, No. 12, pp. 14201426. DOI: 10.1016/j.biortech.2005.06.019

[12] Kaliyan N., Morey R. V., Schmidt D. R. (2013). Roll press compaction of corn Stover and perennial grasses to increase bulk density, Biomass and Bioenergy, Vol. 55, No. 4, pp. 322-330. DOI: 10.1016/j.biombioe.2013.02.031

[13] Heimann R. (2013). Moisture resistant biomass fuel compact and method of manufacturing, Patents, WO, WO/2013/163127. 2013.

[14] Bergström D., Finell M., Gref R. (2010). Effects of extractives on the physical characteristics of Scots pine sawdust fuel pellets, Forest Products Journal, Vol. 60, No.7, pp. 640-644. DOI: 10.13073/0015$\underline{7473-60.7 .640}$
[15] Kaliyan N., Vance Morey R. (2009). Factors affecting strength and durability of densified biomass products, Biomass and Bioenergy, Vol. 33, No.3, pp.337-359. DOI: $10.1016 /$ i.biombioe.2008.08.005

[16] Grover P., Mishra S. (1996). Biomass briquetting: technology and practices, Regional Wood Energy Development Programme in Asia, Bangkok, Thailand, pp.10-21.

[17] Loganathan P., Sivapoornapriya C. (2015). Unsteady heat and mass transfer effects on an impulsively started infinite vertical plate in the presence of porous medium, International Journal of Heat and Technology, Vol. 33, No. 2, pp. 69-74. DOI: 10.18280/ijht.330211

[18] Shang C., Sinka I. C., Pan J. (2012). Constitutive model calibration for powder compaction using instrumented die testing, Experimental Mechanics, Vol. 52, No.7, pp. 903-916. DOI: 10.1007/s11340$\underline{011-9542-8}$

[19] Cocks A. C. F., Sinka I. C. (2007). Constitutive modeling of powder compaction - I. Theoretical concepts, Mechanics of Materials, Vol. 39, No.4, pp. 392-403. DOI: 10.1016/j.mechmat.2006.09.003

[20] Khoei S., Keshavarz, S. O. R. Biabanaki (2010). Optimal design of powder compaction processes via genetic algorithm technique, Finite Elements in Analysis and Design, Vol. 46, No.10, pp. 843-861. DOI: 10.1016/j.finel.2010.05.004

[21] Mukhopadhyay N. (2016). Heat conduction model development of a cold storage using EPS insulation, Modelling, Measurement and Control B, Vol. 85, No. 1, pp.18-27.

[22] Nayak M.K. (2016). Steady MHD flow and heat transfer on a stretched vertical permeable surface in presence of heat generation/absorption, thermal radiation and chemical reaction, Modelling, Measurement and Control B, Vol. 85, No. 1, pp. 91104.

[23] Yang W.F., (2016). Curve and press-mounting force forecasting of precision press-fit assembly by finite element analysis, Chemical Engineering Transactions, Vol. 55, No.2, pp.187-192. DOI: 10.3303/CET1655032

[24] Liu J.R., (2016). Flexible manufacturing cell formation of processing workshop based on intelligent computing, Chemical Engineering Transactions, Vol. 55, No.2, pp. 217-222. DOI: 10.3303/CET1655037

\section{NOMENCLATURE}

$\begin{array}{ll}\text { A, B } & \begin{array}{l}\text { constant parameters determined by } \\ \text { empirical data }\end{array} \\ F & \text { Force, } \mathrm{N} \\ \mathrm{t} & \text { time, } \mathrm{S} \\ \mathrm{g} & \text { gravitational acceleration, } \mathrm{m} . \mathrm{s}-2 \\ \mathrm{~d} & \text { the diameter of mould cavity, } \mathrm{mm}\end{array}$

\section{Greek symbols}

$\sigma$ stress, $\mathrm{N} / \mathrm{mm}^{2}$ 